Quantitative Ansätze in den Literatur- und Geisteswissenschaften 



\section{Quantitative Ansätze in den Literatur- und Geisteswissenschaften}

Systematische und historische Perspektiven

Herausgegeben von

Toni Bernhart, Marcus Willand, Sandra Richter und Andrea Albrecht 
Gefördert von der VolkswagenStiftung.

ISBN 978-3-11-052200-6

e-ISBN (PDF) 978-3-11-052330-0

e-ISBN (EPUB) 978-3-11-052337-9

\section{(cc) BY-NC-ND}

Dieses Werk ist lizenziert unter der Creative Commons Attribution-NonCommercialNoDerivatives 4.0 International License. Weitere Informationen finden Sie unter http://creativecommons.org/licenses/by-nc-nd/4.0/.

\section{Library of Congress Control Number: 2018936214}

\section{Bibliografische Information der Deutschen Nationalbibliothek}

Die Deutsche Nationalbibliothek verzeichnet diese Publikation in der Deutschen Nationalbibliografie; detaillierte bibliografische Daten sind im Internet über http://dnb.dnb.de abrufbar.

(c) 2018 Toni Bernhart, Marcus Willand, Sandra Richter und Andrea Albrecht, publiziert von Walter de Gruyter GmbH, Berlin/Boston

Dieses Buch ist als Open-Access-Publikation verfügbar über www.degruyter.com. Umschlagfoto: Frank Keller „light room I“

Druck und Bindung: CPI books GmbH, Leck

@ Gedruckt auf säurefreiem Papier

Printed in Germany

www.degruyter.com 